IBIMA Publishing

Journal of Marketing Research and Case Studies

http://ibimapublishing.com/articles/JMRCS/2022/981169/

Vol. 2022 (2022), Article ID 981169, 13 pages, ISSN : 2165-7009

DOI : $10.5171 / 2022.981169$

Research Article

\title{
Current Trends in Digital Marketing Communication
}

\author{
Angela MADAN and Mihai loan ROSCA \\ Marketing Department, The Bucharest University of Economic Studies, Bucharest, Romania \\ ORCID 0000-0002-0089-2171
}

Correspondence should be addressed to: Angela MADAN; angela.madan@mk.ase.ro

Received date: 19 March 2021; Accepted date: 18 July 2021; Published date: 5 January

Academic Editor: Nicoleta Dospinescu

Copyright (C) 2022. Angela MADAN and Mihai loan ROSCA. Distributed under Creative Commons Attribution 4.0 International CC-BY 4.0

\begin{abstract}
In the 21st century, businesses and communicators have faced new challenges. In the era of modern technology, internationalization and globalization, marketing communication implements new tools, trends and opportunities. Internet and technological development have opened up the potential for two-way marketing communication and online as well as offline communications are required for companies. The research motivation is to understand and describe new marketing communication processes. The study's methodology is exploratory research, for evaluating the implementation of modern trends in marketing communication and their role in business. The research is organized in three chapters. The first part of the study analyzes the impact of marketing communication. In the second part, a new approach of marketing communication is evaluated, while in the third part, worldwide trends in marketing communication are described. The dynamic expansion of technologies has left its mark on marketing communication, depending on the culture, and economic development of the countries, as well as the population's acceptance of novelty. The main findings of the research are the following hypotheses: due to the transfer of marketing communication, companies need to adjust to modern market trends, while in a modern society, the marketing communication impact is an essential value. Companies need to implement new technologies in their marketing communication in order to be seen worldwide. The main implication of the article lies in describing new marketing communication processes during the expansion of technologies in different countries worldwide in the last decades. This article contributes to the marketing literature. New marketing trends come with opportunities and challenges during the emergence of new technologies.
\end{abstract}

Keywords: marketing communication, digitalization, modern trends

JEL codes: M30, M31, M39

Cite this Article as : Angela MADAN and Mihai Ioan ROSCA (2022), "Current Trends in Digital Marketing Communication", Journal of Marketing Research and Case Studies, Vol. 2022 (2022), Article ID 981169, DOI : $10.5171 / 2022.981169$ 


\section{Introduction}

Marketing has been an important "catalyst" in the process of economic development. Marketing communication sparks interest among general public and marketers. The present time is represented by the ongoing process of globalization in the world economy. In this recent economic reality, multinational enterprises have become key players with their rapidly growing shares in world production, investment and trade flows. This is an interesting phenomenon which needs to be studied, explained and understood in order to outline the contribution made in businesses in different countries. The research objective of this study is to elucidate and to present the evolution of marketing communication during technologies expansions. The research methodology of the article is an exploratory research. This paper aims to carry out an office study to explore modern new trends in marketing communication and their impact on the business of Chinese, Czech, Danish, Latvian, Montenegrin, Romanian, Russian, Slovak and Spanish markets. This research was carried out in order to test and develop the role of marketing communication activity.

The role of new technology in marketing communication in terms of creating responsible business is analyzed through a case study based on secondary sources. This paper explores worldwide marketing communication contribution. Studying modern marketing communication is considered to be a notoriety topic, not enough studied. New trends in marketing communication effects were investigated in marketing applications to question their effects on business. The authors of this paper started a study in order to understand and describe new marketing communication processes. They set out to do an exploratory research for evaluating the implementation of modern trends in marketing communication and their role in business environment in different countries during the last decades. The purpose of this study is to classify the new marketing communication phenomena in order to know their essence and nature.

The main contribution of this article lies in describing the transitional period of marketing communication worldwide. The study adds to the "body of knowledge" the notions of marketing communication, its new modern trends during the expansion of technologies and their effects on business evolution worldwide. This research has some limitations as specified, being based on secondary data. Also, marketing communication was analyzed as a complex phenomenon and was limited by a strict number of countries studied. It can be concluded that new technologies and new marketing trends have revolutionized marketing communication. The findings of this study indicate that digitization tend to unify marketing communications through a global trend, while some companies or countries that were not ready to implement digitalization in the current reality of social distances, should change their strategies.

\section{The Impact of Marketing Communication}

Marketing communication links the company with its market. Company messages should be fitted to "social, cultural, and technological changes" in order to stimulate the process of selling (Dejnaka, 2017), where a customer perceives an offering, product, service, company or person (Finne and Gronroos, 2017). Modern technologies and globalization changed the world. Technology and information society seems natural and is widely used in marketing communication. The globalization process increases the "sense of community among people"; however, it creates barriers between generations (Dejnaka, 2017).

Marketing communication is "the voice of the company and its brands". Marketing communication has been defined as a complex of "measures, techniques and methods" that has economic objectives, influencing management outside the company, and whose efforts are directed at 
consumers. Marketing communication may also be a form of propaganda of a company that "attempts to inform, persuade and remind" about the company image and maintain successful corporations with the target customers. "In the era of mass communications and emerging mobile technologies", a company or a person must build a mix of marketing communications. Marketing communication mix is the combination of many elements such as: advertising or advertisement, personal selling, sales support or promotion, public relations, direct marketing (Todorova, 2015) and digital media (Kupec, Lukác, Štarchon and Bartáková, 2020).

Advertising is "an impersonal form of mass communication" used for "political, economic or cultural" purposes to inform, persuade and promote ideas, products, brands or services "paid by the apparent source", and a reminder for creating "additional utility impact on people's perceptions".

Personal sales include marketing activities by "adding value to products for a limited period of time" and are, as usual, a two-way communication in which the seller "persuades and helps the buyer decide to purchase".

Sales promotions are a supplement, focusing on the immediate effect, which aim to encourage clients to make immediate purchases; however, they do not substitute the "basic benefits" of products.

Public relations are focused on the company, not on the product, covering all communications responsive to constantly inform and influence public opinion. They include "a set of activities" that intend to improve the company's image.

Direct marketing includes targets, budgets and strategies by which a company communicates directly with its "target customers" to generate reaction and/or transaction.
The Internet and mobile technology have contributed to the expansion of the company's products and interaction with customers through "social media, websites, mobile applications, e-commerce, online promotions, etc".

A "powerful" marketing communication mix must be based mainly on respecting customers' confidentiality, ethical and legal differences, as well as "adhering to social norms" and government regulations for contributing to the company's growth. For an effective marketing communications program, the company must adopt an applicable marketing strategy that is coordinated with all marketing activities. Moreover, for a company to be successful, its products must be of high quality, their price must be correctly worded and there should be an adequate distribution channel to its customer (Todorova, 2015).

The traditional perspective on marketing communication is a single-source communication (Finne and Gronroos, 2017) that had limited feedback available via "the market research techniques". The technological development, and from a communication perspective, the development of the Internet have opened up the potential for a "two-way communication" by creating opportunities for "consumers to share and discuss information with each other and with companies and brands" (Kitchen and Proctor, 2015). Several communication sources with an internal planning methodology lead to traditional Integrated Marketing Communication "as the company attempts to integrate all outgoing messages into one voice". The Integrated Marketing Communication approach includes both "traditional media and other means of communication, as well as product and service encounters".

It is important for a company "to take account of what is to be integrated and who is doing the integration". The value of communication is skilled "before, during and after a service is experienced". Providing customers with messages or memories of earlier experiences, through marketing communication channels, may 
also be done through word-of-mouth or social media, or others. Professionals and researchers described "the influence of factors and activities on the customer's network" as structured along two dimensions: "time and situation" that vary between individuals. The notion that "value emerges for the customer in the form of value-in-use" emphasizes a customeroriented focus. It is the messages that emerge the value of communication for customers. The marketer involves modern technologies for informing about customers, and then plans and implements them in activities and communication channels (Finne and Gronroos, 2017). From all previously mentioned arguments, the following research hypothesis was derived:

Hypothesis (H1): Due to the transfer of marketing communication from the traditional to the modern approach, companies need to adjust to new market trends.

Marketing communication is an important and integral part of marketing. In the era of modern technology, internationalization and globalization, marketing communication implements new tools, new trends and new opportunities. International marketing communication was defined as a "cross border communication with target audiences on all issues that influence marketing and business performance". It engages a deeper understanding of "the cross-cultural customers' behaviors and cooperation between companies with different organizational cultures and adapts the messages towards the target audience, which is significantly more diversified" (Grybś, 2014).

There are differences between countries in terms of using the Web in marketing. The web consumer is using high data transfer speeds in the USA and Korea, while UK organizations exhibited a "strategic intent" to its use in marketing over time, in comparison to Australia and New Zealand (Adam, Vocino and Bednall, 2009).

After the Second World War, marketing was directly linked to culture and "the interconnection of culture and marketing" was even defined around the beginning of the twenty-first century. Modern marketing aims to create a value for customers and "to capture value from customers in return", finding its implementation in culture. Marketing communication is an audience-centered activity, bundled into one context of "information, benefits, attributes, perceptual image/persona, feelings, and attitudes" that impacts customers' views on the company, leading to the formation of "unique and positive associations". For effective communication, the seller or sender and the customer or receiver of the communication, "need to be interconnected".

As a consequence of international trends, the digital reality and the continuous cultural changes experienced by society, new challenges are brought in the cultural sphere and museums as well. Museums form "an important part of society" and marketing communication researchers intend to identify and understand the preferences, emotions and reactions of museum visitors. A key indicator of a nation's development is its cultural and creative industry. Museums fulfill cultural, scientific and educating roles toward the society by its main objective "to collect, store, research and exhibit art pieces" (Kupec, Lukác, Štarchon and Bartáková, 2020). According to these contributions, the following research hypothesis is substantiated:

Hypothesis (H2): In a modern society, the marketing communication impact is an essential value.

\section{New Approach of Marketing Communication}

In the 21st century, businesses and communicators face new challenges, as the growing competition brings to the fore the vital essence of business, namely customers. Customers are more sophisticated, demanded, critical and discerning "to business practices" and brands that they stand for. The technological progress is gaining ground and is opening up "new dimensions" of 
communication that require online and offline communications. The social distancing, expansion of networks, and developed social media challenge traditional media and contribute to the prompt transmission of news worldwide. Companies have become visible and the information accessibility in one geographic market is possible through "global media" to consumers via television, computers or mobile phones (Kitchen and Proctor, 2015) that facilitated customer-customer and customer-company interaction (Rust, 2020). World communications are dominated by touch-screen lap-tops, computers, and mobile phones with Internet access (Kitchen and Proctor, 2015) as well as with Internet in smart phones (Rust, 2020). Even face-to-face conversations via these tools allow the development and support of interpersonal relationships and discussions about brands, and companies worldwide (Kitchen and Proctor, 2015).

In marketing communication, new phenomena and trends are noted as a result of "advanced technological solutions and the collapse of trade barriers" and consequently the improvement of message exchange and communication (Grybś, 2014). The Internet has created "a world of virtual reality" where corporations, brands and consumers can interact. The internalization of available information and data, as well as modern technologies and structures enable people to facilitate "the flow of information, thoughts and opinions". Many companies tend to connect directly with customers to best serve them, while other companies (such as "BT and energy suppliers in the UK") prefer "complex electronic firewalls" of consulting the company's website and tend to avoid direct modalities of communication with their customers, with few exceptions.

The development of contemporary marketing processes tends to list word-ofmouth communication, defined as the "information from brand providers and online commentary" from users and nonusers, as one of the most powerful and effective ways to spread popular and sales products, brands or ideas with an influence on the consumer's choice (Kitchen and Proctor, 2015). Word-of-mouth has become a natural result as people become geographically mobile (Rust, 2020). Consumers tend to be influenced by other consumers' opinions in purchasing through interacting online or based on information from social media or corporate websites and online formats as forums, chats, blogs, or others. The predictors of the electronic word-of-mouth motivations were studied during past decades by researchers.

A link has been determined between social media users' personalities and their motivations to "deliver word-of-mouth online". Personality influences were also analyzed, in the sense of how people with different personality types are motivated to deliver word-of-mouth in social media. Studies indicated that persons with extraversive and open personality tend mostly to deliver their positive experience through word-of-mouth online. Influencers offer conversation topics about a brand in social media for some rewards, mostly for social acknowledgement and self-esteem (Anastasiei and Dospinescu, 2018).

Persons tend to perceive disinterested as well as remunerated electronic word-ofmouth messages with confidence. The receiver of word-of-mouth messages perceives non-incentivized messages with a satisfactory level of credibility, while remunerated messages require the transmitter to be an expert. However, the persuasive message content needs to be of high quality in order to have credibility. The electronic Word-of-Mouth spreaders must create and distribute credible and persuasive messages for receivers to act in accordance with them (Anastasiei, Dospinescu and Dospinescu, 2021). As a result of "the underlying technological revolution and in the face of ongoing recessionary influences", marketing communication is changing its shape "metamorphosing into new configurations and forms". And consumer begin to exert influence and control "over marketing processes" through word-of-mouth (Kitchen and Proctor, 2015). 
Marketing is changed by technological, socioeconomic and geopolitical trends (Rust, 2020). Zaušková and Rezníčková (2020) referred to SoLoMo marketing, representing "multi-channel communication strategies" which connect - social media (Social), geolocation services (Local) and mobile devices (Mobile). This concept refers to displaying, on a mobile device, the access to locally oriented "advertisements and sale offers" according to an exact geographical location. Geotargeting is applied with the customer's consent "to provide his location to third parties" by means of geolocation services or applications, as Foursquare, Google Maps or others.

In the same sense, some international marketing communication tools can be mentioned such as "ambient advertising, mobile marketing, social media, internet of things or guerrilla marketing". Also, it is noted that traditional or old-fashioned tools, such as the original landline (Rust, 2020), are displaced by more modern, sophisticated and unconventional marketing communication tools because consumers became more challenging.

Social media created new trends in marketing communication. It can be noted that the main categories of international marketing communication have engaged different media, mainly the television and Internet. The main channels of media engaged are: "radio, television, magazines, newspapers, Internet, outdoor, sales promotions, personal selling and special events". Market players are behaving carefully in "an uncertain economic environment". The international marketing communication market is supplied by companies with certain budgets for communicating with the market "by purchasing the services provided by advertising agencies, interactive agencies and media houses".

Social media marketing may be considered as a separate trend of online marketing that uses various media networks, involving the social sharing of videos and images of the content, to achieve marketing goals and actively involve the consumer. Social media is associated with Facebook as the main platform. Tumbir, Twitter, Youtube and Google+ are listed as the second "most popular social websites in the world". Pinterest was "the fastest growing social website in 2012", and Instagram had a fast growing trend in 2013, becoming part of Facebook. Most global traders as well as Polish ones are engaged in social media.

Mobile marketing can be considered a promising tool of electronic communication. It is a set of practices of communication between organizations and the public or through a "mobile device or network". Nowadays, mobile marketing has evolved and taken on a new dimension. The internet has made "pull type" messages possible, and Location-based marketing has become accessible, being identified by GPS technology.

The Internet of Things is defined as the third wave of the Internet. It is the network of physical objects (Rust, 2020) that can directly or indirectly collect, communicate, process or exchange data "with each other and with people" through built-in sensors using the computer network (Dejnaka, 2017) or Internet access. It is believed that it will lead to the end of the "mobile marketing era" (Grybś, 2014). IKEA has decided to use the internet of things strategically, creating integrated furniture (tables and lamps) with wireless charging technology for mobile devices and wireless chargers "based on Qi technology" (Dejnaka, 2017).

Recently, there have even been ideas about connecting the human brain to the Internet. This network is intending to adopt the prospective that information could be sent from the human brain to the Internet or from the Internet to the brain, or "people can even directly communicate with others" or share memories. This complex Phenomenon, being defined as the Internet of Brains, must be tested and developed (Rust, 2020). Cannes Lions's winning campaign is a symbol of "the new trend in the outdoor part of the international marketing communication" which attests that advertisements have become a part of citizens' everyday life, increasing the trust 
and true emotions' "arousal between the customer and the brand" (Grybś, 2014).

Internet or online marketing, being already a part of the corporate company's identity, created a leap forward. It is defined as the way to achieve marketing goals (Bačík and Fedorko, 2013) in order to increase the amount of communication information (Rust, 2020). The term e-marketing implies internet marketing, but it also includes Mobile marketing. It can be defined as the use of the Internet and information/communication technologies in order to achieve marketing objectives (Bačík and Fedorko, 2013). In a technological era, one can also describe new approaches of marketing communication with respect to marketing activities as "augmented reality, QR codes" (Quick Response), chatbots, and infographics.

Augmented reality is a system or software that connects cameras and sensors, "recognizing elements located in the given territory" by scanning the real image and adding virtual information to this visible image by linking "products offered by the company" on the given platform, and the image can be rotated with the movement of the hand. Augmented reality can be seen on phones or tablets. It can also be applied in outdoor campaigns, at points of sale, at events, fairs, business meetings or parties. In its stores, IKEA uses augmented reality applications in marketing, allowing the visualization of the arranged interior, using the furniture from its catalog and offering the customer the possibility to select the interior arrangements in a perfect way.

QR codes or photo codes are the graphic form used in marketing. They are twodimensional with coded data. Codes transmit data in a creative way such as: a web page, Facebook or Instagram profiles; as a footnote with contact details, as in contact data with "calling card"; event related information being coded and transferred to the phone calendar; e-mail or SMS "after scanning the code"; and Wi-Fi network data. QR codes are mainly applied to transmit marketing communications of organizations and in-store promotion campaigns. In Poland, the $\mathrm{QR}$ code is frequently used in the grocery store, from the simplest form (leading to the main page of the manufacturer) to the reference, to a specially prepared content.

Chatbots, being based on artificial intelligence, are a special computer software "aimed at making conversation with the user", and are frequently used to present "the offer to customers", to answer asked questions and allows full service nonstop. Chatbots are used in Poland in big enterprises, public institutions and banks. The most modern holographic chatbots are utilized for servicing clients in airports, shops or public service places. Other bot variants can also be mentioned such as: knowbot - to gather, manage and "give access to the knowledge"; lingubot - to initiate dialogue and keep conversation and interaction with customers; mindbot - to solve problems with "solution's based on introduced data"; and shopbot - to assist in sales in Internet shops.

New image technology, "applied in marketing communication", is 360-degree films/multimedia, or spherical films along with the most immersive experience of using goggles for virtual reality (e.g. "Google Cardboard or Samsung Gear VR"). A customer can be situated inside the film and freely looks around with different angles of view.

Not only the Internet of Things, but also new innovations like "the wearable technology and smart and simply ones" are recently used in marketing. Wearable technologies aim to collect information and gather data, concerning one's pulse, physical activity, sleep quality as well as data for users' other purposes. This also includes intelligent products or gadgets that make consumers' everyday life easier such as the elastic bracelet "integrated with a Smartphone", or intelligent watches, bands and glasses that allow their user to manage several tasks including payments (Dejnaka, 2017). In the same sense, intelligent products can also include evolving web technologies, like mobile payments, e-wallet or "mechanisms like 3D Secure". 
E-money or electronic currency is "the digital equivalent" of cash. Electronic money can be used in both the real and virtual world. Firstly, it can be used by "inserting a card in a terminal", and by using a wireless technology. Secondly, it can be used via the Internet "from a computer or mobile phone" (Dospinescu, 2012). Any product can be "smart and simple" if granted a specific intelligence, but telephones and watches are most commonly known (Dejnaka, 2017).

Artificial intelligence tends to have an even greater impact on business than social media. It is defined as "the use of computerized machinery to emulate capabilities once unique to humans". Artificial intelligence is widely incorporated in the business of modern companies. Modern automobile factories mainly involve artificial intelligence robots or telephone automated menus. The amount of data recently collected about customers in large databases "has become known as Big Data". This has been possible due to advances in the communications technology, advances in data storage capacity and advances in the computing speed of companies (Rust, 2020). According to this specific specialized literature, the following research hypothesis was formulated:

Hypothesis (H3): In today's reality, a company, in order to be seen worldwide, must implement new technologies in its marketing communication.

\section{Worldwide Trends in Marketing Communication}

Over time, marketing communication revealed specific cultural norms that differ from one country to another around the world. It also presents an "interdisciplinary nature" with rational and emotionalaffective messages based on the countries culture. Marketing communication defines different aspects and stages of digitization in different countries of the world. The dynamic expansion of technologies has left its mark on marketing communication, depending on the country's culture, economic development, as well as population's acceptance of novelty. New marketing trends came with opportunities and challenges during the emergence of new technologies. For the comparability of the data, the implementation of the marketing communications concept was analyzed in the following countries in the light of the last two decades.

In China, the Chinese modern advertising, as a part of marketing communications, harmoniously interact with the traditional culture, "socialist ideas", and new advanced cultural practices and technologies. It includes the acceptable components within its own worldview. China, after the USA, is the world's second largest marketing communication industry with a high consumption and constantly rising expenses. Family is a fundamental Confucian value. The supreme value for a Chinese person is having a successful marriage with a dignified person and after that a successful career. There are some qualities of a traditional Chinese society that must be perceived by marketers such as: "frugality, domesticity, face-saving, virtues being more important than money, utmost respect for traditions, modesty, and humility with regard to other people". There are evidences of the existence of superstition in the Chinese marketplace. For example, price endings used in advertisements show a tendency to favor using digit 8 (associated with prosperity and good luck) and to avoid using digit 4 (associated with death). Likewise in Chinese marketing communication, the Chinese Dream stands out as part of the world dream. There were remarkable differences between the Chinese Dream (based on the "national revival, general prosperity, democracy, and people's happiness") and the American Dream (based on "highlighting personal freedom, individual success, and an upward movement on the social and economic ladder").

Moreover, the Chinese advertisement harmoniously adopts its culture, healthy environment, collectivist origin, equality and rectitude, same life standards of rural and urban people, laconism, happy people being represented, rejuvenation of the 
nation, ancient traditions, rituals and symbols, images with harmony of nature, the environment, "principles of the male and female"; female symbols, a semiotic orientation on "the other cultures" and the global components acceptable to the country. In Chinese marketing communication, the combination of global and traditional cultures with the main idea in traditional values is evident (Koptseva and Reznikova, 2017).

Family is "an integral and fundamental" part of the society. It is a group of people linked by marital, family or relationships "based on a common way of life" to create a community "engaged in building something that lasts" for future generations. A family business is "a lifelong work", and marketing is the life view of "a modern person in the context of a sustainable development philosophy".

The theory of general business vitality, after research in the Czech Republic, concluded that family and non-family businesses are using value marketing. Through marketing communication, they are building long-term satisfaction, "consequently customer loyalty" and favoring intuitive marketing tools. Marketing strategies applied by Czech family businesses need to re-evaluate the perception of customers' current needs and to modernize marketing communication. They need to adopt new marketing strategies and communication techniques to meet customers' expectations. This could be done by online communication, social media, virtual reality, etc. (Petrů, Havlíček and Tomášková, 2018).

Marketing is an art (creative side) and science (theoretical side). The behavior of "Czech social media users" reflects the worldwide trend. However, some companies with a Czech base do not respond effectively to this trend. Unlike the American companies, where social media is a key marketing communication tool, Czech companies are not monitoring business trends and they are even neglecting marketing (Svatošová, n. d.).
Marketing communication forms the groundwork for relationship development. It plays a central part in the company's atmosphere and a decisive role in the marketing process. Andersen (2001) conducted a research on the fourth largest retail and the largest savings bank in Denmark. It was recommended to develop the role of rhetoric in marketing communication that is linked to performance in relationships in order to analyze if this strategy affects organizations' ability to develop customer trust, commitment and maintain relationships. In the marketing of banks, "relationship marketing" has a strong position. It was mentioned that in marketing communication, rhetoric develops the "decision-making awareness" (Andersen, 2001).

The current market situation in Latvia had a trend toward integrated marketing communications that coincides with the global trends. In Latvia, there are some barriers and obstacles which interfere with the implementation of integrated marketing communications such as: insufficient knowledge of marketing directors, lack of competence in program design, implementation of services of insufficient quality, limited specialization of marketers or lack of resources (Dmitrijeva and Batraga, 2012).

Digital forms of marketing communication like the Internet, social networks, and "mobile phone services" are considered as an opportunity for the whole world as well as for Montenegro. A study on 172 companies from Montenegro analyzed the influences of using digital marketing transformation in business and its impact on promotion or brand positioning. Recently, $74 \%$ of the country's population have Internet access and actively use social networks. The effect of using digital marketing communication in Montenegro is significant in promotion and increases brand awareness, leading to a better positioning (Melovic, Jacovic, Dabic, Vulic and Dudic, 2020).

Romania is distinguished by its natural component and the historical component 
as well as "the cultural heritage". Romania registers a treasury of archaeological traces, "historical, architectural and art monuments", a valuable patrimony certifying the "continuous and life evolution", art development and Romanian culture (Tigu, Cristache, Mahika and Totan, 2014). In Romania, along with the dynamic expansion of modern technologies in marketing communication, the increasing role of the electronic word-of-mouth was noted. In order for "online marketing campaigns to be successful", messages type must be of high quality or credible and the message transmitter/source should be highly trusted (Anastasiei, Dospinescu and Dospinescu, 2021).

Integrated marketing communication is a new phenomenon in Russia. It is influenced by the intuitive practices and emergent vectors. Russian organizations focus on the spread of positive information and underestimate the importance of open and public communication. Consumer choices represent the regional market specifics in Russia, but the professional implementation of "communication integration" is still intuitive. It varies at different Russian companies, and marketing communication profession is seen as "peripheral" to the organizational development (Endaltseva, 2015).

Modern marketing communication strategies of the Slovak business require the implementation of digital marketing as a global trend. As a result of analyzing 300 Slovak businesses, it was noted that a part of the companies' strategy that use social networks for marketing communication is to plan their "posts and content in advance". Social media is the most widespread and accessible type of digital media. Many Slovak businesses are using social media (as Facebook, Instagram and YouTube) in eco-innovation processes. The implementation of mobile devices "into the marketing strategies" of businesses is necessary. Slovak companies do not use the potential of digital marketing communication (Zaušková and Rezníčková, 2020).
The analysis of 301 marketing directors of Spanish companies and different online, digital competence communication techniques of professionals has pointed out to the trends of companies to increase the "budget for digital marketing communication". The United States' digital marketing communication continues the trend of growing "above conventional advertising". Spanish companies prefer conservative, "easy-to-implement" techniques, to more sophisticated tools that require specialized knowledge, preparation and a specific, costly technology. Largesized Spanish marketers use sophisticated marketing communication techniques unlike small-sized companies which use "a smaller variety" of digital marketing communication or common, traditional techniques to connect with consumers (García, García and Blanco, 2017).

\section{Conclusion}

Marketing communication topic is of great interest to both practitioners as well as academics. Researchers, depending on the place and reason for developing a marketing communication study, approached certain points of interest. The authors of this paper withhold that most authors approach marketing communication development as a concept adaptable to business. In this context, the implications and findings of this research will help analyze and elucidate the role of marketing communication, new trends and worldwide modern implementation. The increasingly important role of communication is reflected in other areas of society. When analyzing the evolution of marketing communication, one can elucidate the important role it has played over the years along with the major changes resulted from the emergence of new technologies. The review allows formulating the research hypotheses. This research confirms the hypotheses regarding marketing communication transformation during the past two decades. The positive relationship between the companies' adjustment to new market trends and marketing communication transformation was proved by Kupec, Lukac, Starchon and Bartakova (2020), 
Todorava (2015), Kitchen and Proctor (2015), and Finne and Gronroos (2017). Also, the positive relationship between the modern society and the essential value of marketing communication was affirmed by Grybs (2014), Adam, Vocino and Bednall (2009), and Kupec, Lukac, Starchon and Bartakov (2020). Moreover, the positive relationship between the present reality and the company's necessity of implementing new technologies in its marketing communication, in order to be recognized worldwide was reasoned by Rust (2020), Zauskova and Reznickova (2020), Dejnaka (2017), Grybs (2014), and Bacik and Fedorko (2013).

This study also investigates marketing communication implementation during the expansion of technologies in the last decades in order to understand and describe new marketing communication processes in different countries. This represents the main contribution of this article, namely describing the transitional period of marketing communication worldwide. The study contributes to the marketing literature. First, this case study adds to the "body of knowledge" the notions of marketing communication and their effect on business. Second, this study assesses the new modern trends in marketing communication and their worldwide evolution. Third, the study shows that the web marketing tends to unify marketing communication as a global trend. It can be concluded that new technologies and new marketing trends revolutionized marketing communication. Different countries' businesses face this new reality.

This research has several limitations. In the first place, this is an exploratory study based on secondary data and this limits the actuality of the findings. Another limitation of the research is the fact that marketing communication was analyzed as a phenomenon as a whole in the countries studied. This suggests that the analysis of each element of the marketing communication mix could provide an important perspective on the issue of implementation and adjustment at each stage. Also, the study is limited due to the strict number of countries analyzed. A larger study, in terms of the level of transformation of marketing communication in several countries, can provide valuable information. However, significant preliminary conclusions were provided in this study. Additionally, this study is considered to be a contribution to the body of academic literature by identifying the strategic roles of the technological implication in the marketing communication context and developing a unique worldwide marketing communication framework in a globalization era.

Finally, this study will contribute to the further research for many prominent researchers who express their doubts about the state and future of marketing communication studies, characterized by contradictory and confusing empirical findings. A larger quantitative study on companies' marketing communication from different countries is recommended as a future line of research. The future direction of research could also examine marketing communication in terms of individual particularity and country traditions in order to encourage the unique worldwide model development with a national specificity depending on the region.

Marketers have faced a number of opportunities and challenges due to the rapid evolution of digital marketing. The managerial implications based on the study are as follows. From a managerial perspective, and from a scientific research, the results of this study lead to the conclusion that some companies allow marketers to lead the strategy, while others do not attach importance to digitization and develop, at best, marketing communication intuitively. This research is useful for the business environment in order to develop a successful online marketing campaign based on digitalization and to achieve its desired goal in a globalization era.

Furthermore, the findings of this research indicate that in marketing, digitalization and web tend to unify marketing 
communication as a global trend. Due to the dynamic expansion of technologies and social distancing, companies from different countries that were not ready to implement digitalization in marketing communication, are now forced to deal with it. In conclusion, worldwide companies in the current conditions faced real changes and may need to modify their strategies in order to be integrated into worldwide marketing communication frameworks. This is the first study to comparatively explore this issue in so many countries. It identifies the range of implementation issues of digitalization and the needed incorporation into marketing communication frameworks during last decades.

\section{References}

- $\quad$ Adam, S., Vocino, A. and Bednall, D. (2009), 'The world wide web in modern marketing's contribution to organizational performance,' Marketing Intelligence and Planning 27 (1), 7-24.

- Anastasiei, B. and Dospinescu, N. (2018), 'A model of the relationships between the Big Five personality traits and the motivations to deliver word-ofmouth online,' Psihologija 51 (2), 215227.

- Anastasiei, B., Dospinescu, N. and Dospinescu, 0. (2021), 'Understanding the Adoption of Incentivized Word-ofMouth in the Online Environment,' Journal of Theoretical and Applied Electronic Commerce Research 16, 9921007.

- Andersen, P.H. (2001), 'Relationship development and marketing communication: an integrative model,' Journal of Business and Industrial Marketing 16 (3), 167-182.

- Bačík, R and Fedorko, I. (2013), 'New Trends in Marketing Communication,' Modern Economy: Problems, Trends, Prospects 8, 39-47.

- Endaltseva, A. (2015), 'The present state of integrated communication in Russia,' Public Relations Review 41, 533-540.
- Dejnaka, A. (2017), 'Technologization of Marketing Communication - New Trend,' Oeconomia 2, 59-68.

- Dospinescu, O. (2012), 'Mobile Payments. from Mobility to Security,' Young Economists' Journal, 190-193.

- Dmitrijeva, K. and Batraga, A. (2012), 'Barriers to integrated marketing communications: the case of Latvia (small markets),' Procedia - Social and Behavioral Sciences 58, 1018-1026.

- Finne, E. and Gronroos, Ch. (2017), 'Communication-in-use: customerintegrated marketing communication.' European Journal of Marketing 51 (3), 445-463.

- García, S.C., García, D.A. and Blanco, T.P. (2017), 'Practices, skills and trends in digital advertising. The perspective of Spanish advertisers,' RLCS, Revista Latina de Comunicación Social 72, 1648-1669.

- Grybś, M. (2014), 'Creating New Trends in International Marketing Communication,' Journal of Economics and Management 15, 156-173.

- Kitchen, Ph.J. and Proctor, T. (2015), 'Marketing communications in a postmodern world,' Journal of Business Strategy 36 (5), 34-42.

- Koptseva, N.P. and Reznikova, K.V. (2017), 'The Cultural Aspects of Advertising Communications in Modern China,' East Asia 34, 249-269.

- Kupec, V., Lukác, M., Štarchon, P. and Bartáková, G.P. (2020), 'Audit of Museum Marketing Communication in the Modern Management Context,' International Journal of Financial Studies 8 (39), 1-13.

- Melovic, B., Jacovic, M., Dabic, M., Vulic, T.B. and Dudic, V. (2020), 'The impact of digital transformation and digital marketing on the brand promotion, positioning and electronic business in Montenegro,' Technology in Society 63, 1-14.

- Petrů, N., Havlíček, K. and Tomášková, A. (2018), 'Comparison of Marketing Vitality of Family and Non Family Companies doing Business in the Czech Republic,' Economics and Sociology 11 (2), 138-156. 
- Rust, R.T. (2020), 'The future of marketing,' International Journal of Research in Marketing 37, 15-26.

- Svatošová, V. (n.d.), 'Social Media Such As the Phenomenon of Modern Business,' University of Pardubice, 1-24.

- Tigu, G., Cristache, S.E., Mahika, E.C. and Totan L. (2014), 'Analysis of the cultural tourism trends and perspectives in Romania,' Journal for Communication Studies 7 (1), 191-207.
- Todorova, G. (2015), 'Marketing Communication Mix,' Trakia Journal of Sciences 13 (1), 368-374.

- Zaušková, A. and Rezníčková, M. (2020), 'SoLoMo marketing as a global tool for enhancing awareness of ecoinnovations in Slovak business environment,' Equilibrium. Quarterly Journal of Economics and Economic Policy 15 (1), 133-150. 